\title{
Effects of the Sense of Stress on Martensitic Transformations in Monocrystalline Cu-Al-Ni Shape Memory Alloys
}

\author{
By H. Sakamoto* and K. Shimizu*
}

\begin{abstract}
The effects of the sense of stress on stress-induced martensitic transformations in monocrystalline $\mathrm{Cu}-\mathrm{Al}-\mathrm{Ni}$ shape memory alloys with 13.8-15.3 mass\%Al have been investigated as a function of temperature above $M_{\mathrm{s}}$ by tension-compression tests using an extensometer. In a temperature range above $A_{\mathrm{f}}, \beta_{1} \rightleftarrows \beta_{1}^{\prime}$ transformations occur on the tension side regardless of the amount of strain, but on the compression side the $\beta_{1} \rightarrow \beta_{1}^{\prime}$ transformation occurs at the very beginning followed by $\beta_{1} \rightarrow \gamma_{1}^{\prime}$ transformation and their reversions do, probably because of a non-uniaxiality under compressive stress. $\beta_{1}^{\prime}$ martensite is first stress-induced on both the tension and compression sides and undergoes a maximum resolved shear stress. Temperature dependence of the critical stress $(\sigma)$ for inducing the $\beta_{1} \rightarrow \beta_{1}^{\prime}$ transformation is larger on the compression side than on the tension side. This result can not be explained in terms of Schmid's law, but can be in terms of Clausius-Clapeyron equation by taking account for a different transformation strain associated with the formation of another variant of $\beta_{1}^{\prime}$ martensite on the compression side. A temperature given by extrapolation of the $\sigma$ vs temperature curve to zero stress is higher on the compression side than on the tension side. This can be interpreted in terms of a difference in constraint condition between the compression and tension sides.
\end{abstract}

\section{(Received May 18, 1984)}

Keywords: shape memory alloy, copper-aluminium-nickel alloy, stress-induced martensitic transformation, transformation pseudoelasticity, tension-compression test, ClausiusClapeyron equation, Schmid's law.

\section{Introduction}

Martensitic transformations have a great influence on mechanical properties of alloys, since they proceed by a shear-like mechanism. In particular, interesting mechanical properties such as shape memory and pseudoelasticity effects have been found in several alloys exhibiting thermoelastic martensitic transformations. Many studies have, thus, been carried out on effects of stress on the martensitic transformations and mechanical properties ${ }^{(1)-}$ (3). By the way, stress may be typically classified into uniaxial tension and compression. A few thermodynamical studies ${ }^{(4)-(6)}$ have treated the effect of compression to be equivalent to that of tension. However, experimental studies ${ }^{(7)-(13)}$ have been performed to distinguish them from each other. Some of the studies were carried out under separate tension and compression.

* The Institute of Scientific and Industrial Research, Osaka University, 8-1, Mihoga-oka, Ibaraki, Osaka 567, Japan.
Burkart and $\operatorname{Read}^{(7)}$ found in a monocrystalline In-20.7 at\% Tl alloy that the slope $d \sigma / d T$ of transformation temperature vs stress curve is larger under compressive stress than under tensile stress. Such a difference in the slopes $d \sigma / d T$ under compressive and tensile stresses was explained in terms of ClausiusClapeyron (C-C) equation and formation of another variant of tetragonal martensites. Patel and Cohen ${ }^{(8)}$ found in non-thermoelastic $20 \mathrm{wt} \% \mathrm{Ni}-0.5 \mathrm{wt} \% \mathrm{C}$ steels that the effect of compressive stress on $M_{\mathrm{s}}$ temperature was appreciably larger than that of tensile stress, and attributed the difference to the existence of normal component of applied stress as well as shear component. Pops ${ }^{(9)}$ failed to find any particular difference between deformation behaviors in tension and compression tests of polycrystalline $\mathrm{Cu}-\mathrm{Zn}-\mathrm{Si}$ alloys at temperatures above $M_{\mathrm{s}}$. On the other hand, a few studies have been performed under continuous tensile-compressive loading. The studies on monocrystalline $\mathrm{Au}_{26} \mathrm{Cu}_{27} \mathrm{Zn}_{47}{ }^{(10)}$ and $\mathrm{Au}-47.5$ at $\% \mathrm{Cd}^{(11)}$ alloys found no particular difference between tensile and com- 
pressive stresses. However, it has recently been found in monocrystalline $\mathrm{Cu}-\mathrm{Al}-\mathrm{Ni}$ alloys that the critical stress $\left(\sigma_{c}\right)$ and also the critical resolved shear stress $\left(\tau_{c}\right)$ for inducing martensites at temperatures above $M_{\mathrm{s}}$ under a compressive stress are lower than those $\left(\sigma_{t}\right.$ and $\left.\tau_{t}\right)$ under a tensile stress ${ }^{(12)}$. This difference between compressive and tensile stresses has been explained in such a way that $\sigma_{c}$ is lowered by buckling due to a non-uniaxiality under compressive stress. However, a more recent study $^{(13)}$ has revealed that $\sigma_{c}$ and $\tau_{c}$ become larger than $\sigma_{t}$ and $\tau_{t}$, respectively, in a higher temperature range. Therefore, the previous explanation must be revised, and the difference between $\sigma_{c}$ and $\sigma_{t}$ or $\tau_{c}$ and $\tau_{t}$ should be explained in terms of $\mathrm{C}-\mathrm{C}$ equation as the one between $d \sigma_{c} / d T$ and $d \sigma_{t} / d T$. The present study has, thus, been carried out to closely verify the revised explanation, by carefully examining tensile-compressive deformation behavior of monocrystalline $\mathrm{Cu}-\mathrm{Al}-\mathrm{Ni}$ shape memory alloys with $13.8-15.3$ mass $\% \mathrm{Al}$ as a function of temperature above $M_{\mathrm{s}}$, an extensometer being used. On the basis of experimental results on $d \sigma / d T$ and so on, discussion will be done on some incompatibility between the C-C equation and Schmid's law.

\section{Experimental Procedures}

$\mathrm{Cu}-\mathrm{Al}-\mathrm{Ni}$ alloys were prepared by melting the component metals in a high frequency induction furnace under argon atmosphere. Single crystals of $\sim 10 \times 10 \times 80 \mathrm{~mm}^{3}$ size were grown from ingots of the alloys by a modified Bridgman method. The final heat treatment for the single crystals was as follows:

$$
1273 \mathrm{~K} \text { for } 7200 \mathrm{~s} \rightarrow \mathrm{W} . \mathrm{Q} \text {. at } 273 \mathrm{~K} \text {. }
$$

Then, specimens for tension-compression tests were spark-cut from the heat treated single crystals. Dimension of the gauge length portion was $5 \times 5 \times 10 \mathrm{~mm}^{3}$ (except for $\mathrm{Sp} .7$ of $\left.5 \times 5 \times 16 \mathrm{~mm}^{3}\right)$. Chemical compositions and characteristic temperatures of the specimens are shown in Table 1, and orientations of the specimens in Fig. 1.

The tension-compression tests were performed by means of an Instron Machine (TT-CM-L type) equipped with a constant temperature chamber, the strain rate $(\dot{\varepsilon})$ being $4.8 \times 10^{-4} \mathrm{~s}^{-1}$. Stress-strain (S-S) curves were recorded by using a dynamic extensometer unless otherwise stated. The zero point of stress was deliber-

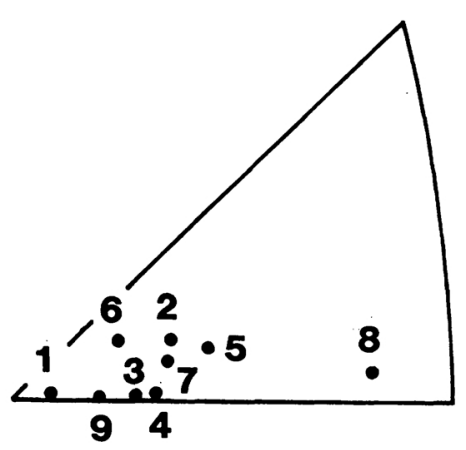

Fig. 1 Orientations of the specimens used.

Table 1 Chemical compositions and characteristic temperatures of the specimens used.

\begin{tabular}{cccccccc}
\hline \hline \multirow{2}{*}{$\begin{array}{c}\text { Sp. } \\
\text { No. }\end{array}$} & \multicolumn{3}{c}{ Composition /mass \% } & \multicolumn{5}{c}{ Characteristic Temperature/K } \\
\cline { 2 - 8 } & $\mathrm{Cu}$ & $\mathrm{Al}$ & $\mathrm{Ni}$ & $M_{\mathrm{s}}$ & $M_{\mathrm{f}}$ & $A_{\mathrm{s}}$ & $A_{\mathrm{f}}$ \\
\hline 1 & bal. & 13.8 & 4.2 & 297 & 288 & 308 & 337 \\
2 & $\prime \prime$ & 13.8 & 4.2 & 295 & 278 & 298 & 337 \\
3 & $\prime \prime$ & 14.1 & 4.1 & 271 & 255 & 278 & 314 \\
4 & $\prime \prime$ & 14.8 & 4.2 & 188 & 178 & 203 & 212 \\
5 & $\prime \prime$ & 15.1 & 4.2 & 163 & 153 & 181 & 188 \\
6 & $\prime \prime$ & 15.3 & 4.1 & 148 & 271 & 185 \\
7 & $\prime \prime$ & 14.0 & 4.0 & 267 & 242 & 273 & 299 \\
8 & $\prime \prime$ & 14.1 & 4.2 & 291 & 273 & 281 & 316 \\
9 & 13.9 & 4.2 & 293 & 274 & 295 & 333 \\
\hline \hline
\end{tabular}

*below liq. $\mathrm{N}_{2}$ temperature 
ately adjusted, because it was important for absolute comparison between $\sigma_{c}$ and $\sigma_{t}$. Macroscopic and microscopic observations during deformation and X-ray back reflection Laue photography from stress-induced martensites (SIM) under stress were carried out by using a small tension-compression device.

\section{Results and Discussion}

\section{Comparison between S-S curves measured with and without extensometer}

In a preliminary tension-compression test, the use of extensometer has been known to be very important to obtain more precise S-S curves, as seen from Fig. 2 which shows a comparison between the S-S curves recorded with, (a), and without, (b), an extensometer. Two differences are recognized between them. One is that the elastic strain in (b) is beyond $2 \%$ but that in (a) within $1 \%$, indicating, needless to say, that strains other than the gauge length portion are included in (b). The other is that sharp peaks, which are suggestive of a formation of $\gamma_{1}^{\prime}$ martensite ${ }^{(14)}$, appear at the yield points in (b) but not in (a). The origin of the absence of sharp peaks may be explained as follows. When a $\gamma_{1}^{\prime}$ martensite once formed grows faster than the crosshead speed, a load imposed on the specimen should be relaxed. In such a case, the use of extensometer enables one to measure the transformation strain $(\Delta \varepsilon)$ simultaneously occurring with the growth, and therefore, the relaxation of load may be performed rather gradually. Accordingly, the sharp peaks in (b) should be said to be a spurious phenomenon. Therefore, a previous description on S-S characteristics must be properly corrected, which was discussed in terms (a) with extensometer

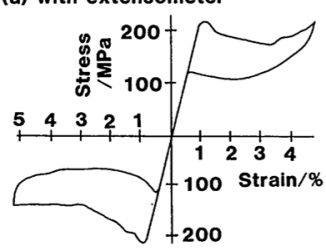

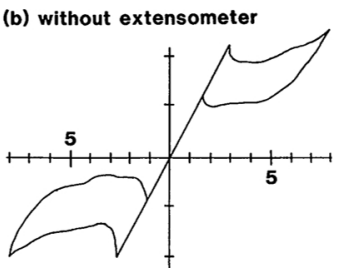

Fig. 2 Comparison between S-S curves obtained with, (a), and without, (b), an extensometer (Sp. 5, at $198 \mathrm{~K}$ ).

of an effective stress for martensite nucleation $\left(\tau_{\text {eff. }}^{\text {nucl. }}\right)$, propagation rate of martensite interface $\left(V_{i}\left(\tau_{\text {eff. }}^{\text {nucl. }}\right)\right)$ and $\dot{\varepsilon}^{(14)}$.

\section{Effect of amount of strain on S-S curves}

Figure 3 shows the S-S curves obtained at temperatures above $A_{f}$, being subjected to various amounts of strain. On the tension side, $\beta_{1}^{\prime}$ martensite is always stress-induced regardless of the amount of strain, as known from the small hysteresis of stress ${ }^{(14)}$. However, the S-S curves on the compression side are different depending on the amount of strain. That is, when strain is small, $\beta_{1}^{\prime}$ martensite is first stress-induced, as seen from the small hysteresis loop, (A). When strain is increased a little, the amount of the hysteresis is increased as seen in (B), and this increase in hysteresis indicates that $\gamma_{1}^{\prime}$ martensite is subsequently stress-induced. The amount of hysteresis almost linearly increases with increasing strain until it is saturated at $5.2 \%$ strain, (B) to (E). The saturated amount of hystresis is con-

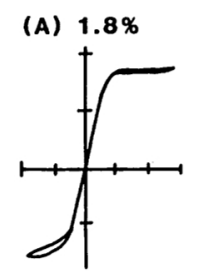

(D) $4.5 \%$
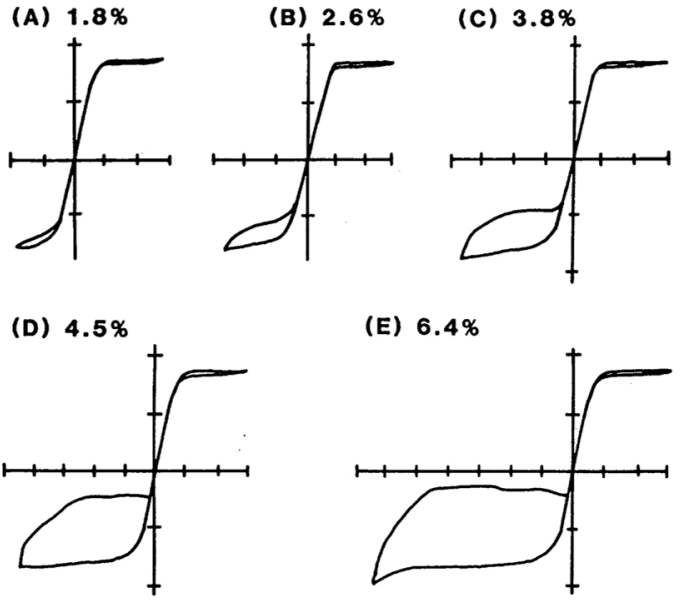

(E) $6.4 \%$

(F) $8.0 \%$

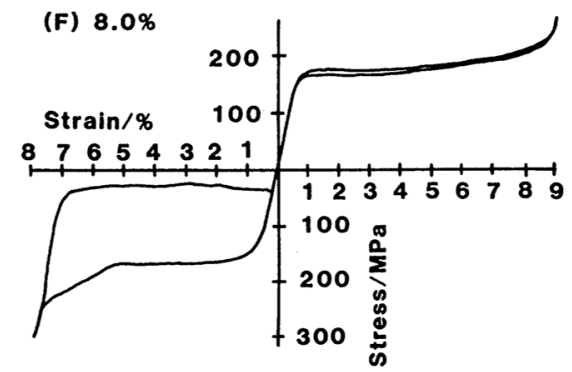

Fig. 3 Effect of amount of compressive strain on S-S curves (Sp. 1, at $355 \mathrm{~K}$ ).

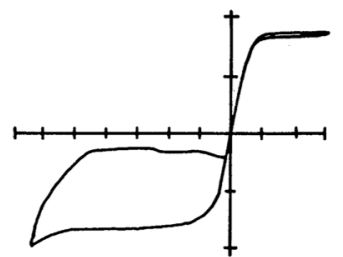


Table 2 Summary of experimental results on $d \sigma / d T$ and their explanations in terms of Schmid's law and Clausius-Clapeyron equation ( $\mathrm{T}$ and $\mathrm{C}$ mean the tension and compression sides, respectively).

\begin{tabular}{|c|c|c|c|c|c|c|c|c|c|c|}
\hline \multirow{3}{*}{$\begin{array}{l}\text { Sp. } \\
\text { No. }\end{array}$} & \multirow{3}{*}{$\begin{array}{l}\text { Observed } \\
\qquad \frac{d \sigma}{d T} \\
(\mathrm{MPa} / \mathrm{K})\end{array}$} & \multirow{2}{*}{\multicolumn{3}{|c|}{ Schmid's law }} & \multicolumn{6}{|c|}{ Clausius-Clapeyron equation } \\
\hline & & & & & \multicolumn{2}{|c|}{ Calculated } & \multicolumn{4}{|c|}{ Experimental } \\
\hline & & $\begin{array}{l}\text { Schmid } \\
\text { factor }\end{array}$ & $\begin{array}{c}\frac{d \tau}{d T} \\
(\mathrm{MPa} / \mathrm{K})\end{array}$ & $\begin{array}{c}\text { Differ- } \\
\text { ence } \\
(\%)\end{array}$ & $\begin{array}{c}\Delta \varepsilon^{\text {cal. }} \\
\left(\times 10^{-2}\right)\end{array}$ & $\begin{array}{c}\frac{d \sigma}{d T} \cdot \Delta \varepsilon^{\text {cal. }} \\
\left(\times 10^{-2} \mathrm{MPa} / \mathrm{K}\right)\end{array}$ & $\begin{array}{l}\text { Differ- } \\
\text { ence } \\
(\%)\end{array}$ & $\left(\times \varepsilon^{\exp }\right.$ & $\begin{array}{c}\frac{d \sigma}{d T} \cdot \Delta \varepsilon^{\exp } \\
\left(\times 10^{-2} \mathrm{MPa} / \mathrm{K}\right)\end{array}$ & $\begin{array}{l}\text { Differ- } \\
\text { ence } \\
(\%)\end{array}$ \\
\hline \multirow{2}{*}{${ }^{1} \stackrel{\mathrm{T}}{\mathrm{C}}$} & 2.14 & +0.492 & 1.05 & \multirow{2}{*}{-3.6} & +8.4 & 17.98 & \multirow{2}{*}{+0.1} & +8.4 & 17.98 & \multirow{2}{*}{+15.6} \\
\hline & 2.19 & -0.498 & 1.09 & & -8.2 & 17.96 & & -7.1 & 15.55 & \\
\hline \multirow{2}{*}{$2 \frac{T}{C}$} & 2.09 & +0.484 & 1.01 & \multirow{2}{*}{-6.9} & +8.2 & 17.15 & \multirow{2}{*}{-2.3} & +8.2 & 17.15 & \multirow{2}{*}{+18.5} \\
\hline & 2.37 & -0.456 & 1.08 & & -7.4 & 17.54 & & -6.1 & 14.46 & \\
\hline \multirow{2}{*}{${ }^{3} \mathrm{~T}$} & 2.28 & +0.500 & 1.14 & \multirow{2}{*}{-3.5} & +8.6 & 19.61 & \multirow{2}{*}{+0.5} & +8.6 & 19.61 & \multirow{2}{*}{+24.0} \\
\hline & 2.47 & -0.479 & 1.18 & & -7.9 & 19.51 & & -6.4 & 15.81 & \\
\hline \multirow{2}{*}{$4 \begin{array}{l}\mathrm{T} \\
\mathrm{C}\end{array}$} & 2.35 & +0.499 & 1.17 & \multirow[t]{2}{*}{-4.7} & +8.5 & 19.98 & \multirow[t]{2}{*}{+1.3} & +8.5 & 19.98 & \multirow[t]{2}{*}{+22.6} \\
\hline & 2.55 & -0.467 & 1.19 & & -7.7 & 19.64 & & -7.4 & 16.32 & \\
\hline \multirow{2}{*}{${ }^{5} \begin{array}{l}\mathrm{T} \\
\mathrm{C}\end{array}$} & 2.36 & +0.479 & 1.13 & \multirow{2}{*}{-6.2} & +8.1 & 19.12 & \multirow{2}{*}{-4.6} & * & * & \multirow[t]{2}{*}{$*$} \\
\hline & 2.80 & -0.430 & 1.20 & & -7.1 & 19.88 & & $*$ & $*$ & \\
\hline \multirow{2}{*}{$6 \frac{\mathrm{T}}{\mathrm{C}}$} & 2.16 & +0.492 & 1.06 & \multirow{2}{*}{-6.6} & +8.3 & 17.93 & \multirow{2}{*}{-3.6} & +8.3 & 17.93 & \multirow{2}{*}{-4.9} \\
\hline & 2.35 & -0.481 & 1.13 & & -7.9 & 18.57 & & -8.0 & 18.80 & \\
\hline
\end{tabular}

*not measured

sidered to be inherent to the $\beta_{1} \rightarrow \gamma_{1}^{\prime}$ transformation. Such a formation of the $\gamma_{1}^{\prime}$ martensite can be ascribed to an ill uniaxiality in the compression test. That is, a non-uniform stress arising from the ill uniaxiality is more easily relaxed by twinning in the $\gamma_{1}^{\prime}$ martensite than by a formation of another variant of $\beta_{1}^{\prime}$ martensite, because twinning is operative at lower stress level. This interpretation can be supported by the increased amount of hysteresis, because the uniaxiality in compression tests becomes worse with increasing strain.

$\Delta \varepsilon$ associated with the $\beta_{1} \rightarrow \beta_{1}^{\prime}$ transformation can be measured by deforming a specimen until the transformation is completed as in (F). No problem arises in tension tests, since $\beta_{1}^{\prime}$ martensite is only stress-induced, and good agreement between $\Delta \varepsilon_{\text {ten. }}^{\text {exp. }}{ }^{\dagger}$ and $\Delta \varepsilon_{\text {ten. }}^{\text {cal. has been }}$ obtained for all the specimens measured (see

$\dagger$ Superscript of cal. or exp. and subscript of ten. or comp. mean whether the $\Delta \varepsilon$ is calculated from the phenomenological theory ${ }^{(14)}$ or measured experimentally and whether it is under tensile or compressive stress, respectively.
Table 2). On the other hand, $\Delta \varepsilon_{\text {comp. }}^{\text {exp. of the }}$ $\beta_{1} \rightarrow \beta_{1}^{\prime}$ transformation was unable to be successfully measured, because $\gamma_{1}^{\prime}$ martensite is also stress-induced. It is, however, evident that

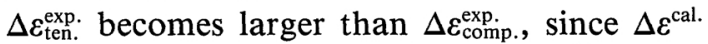
$\left(\beta_{1} \rightarrow \beta_{1}^{\prime}\right)$ is larger than $\Delta \varepsilon^{\text {cal. }}\left(\beta_{1} \rightarrow \gamma_{1}^{\prime}\right)^{(14)}$.

\section{S-S curves as a function of temperature}

Figure 4(A) to (F) show typical S-S curves obtained as a function of temperature, $5 \%$ strain being given on both the tension and compression sides, except $(\mathrm{C})$ and $\left(\mathrm{C}^{\prime}\right)$. The S-S behavior at temperatures above $A_{f}$, (E) and (F), is similar to that in the preceding section. The behavior in the temperature range between $M_{\mathrm{s}}$ and $A_{\mathrm{f}}$ is different depending on whether deformation is started from the tension or the compression side, (A) to (D). When started from the tension side, (B) and (D), a pseudoelastic loop with small hysteresis is obtained on the tension side, and some residual strain is present on the compression side. On the other hand, when started from the compression side, (A) and $\left(\mathrm{B}^{\prime}\right), \gamma_{1}^{\prime}$ martensite remains upon release of the compressive stress, and so 
(A) Sp.1, 303K

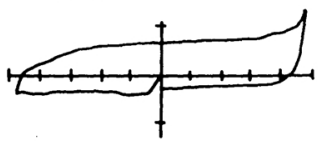

(B) 308K

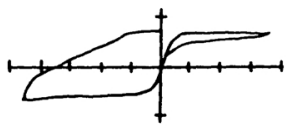

(D) $333 K<$ At

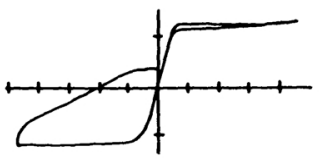

(G) Sp.4, 208K $<A$ I

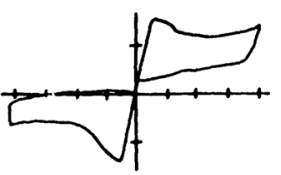

(E) $353 K>A$

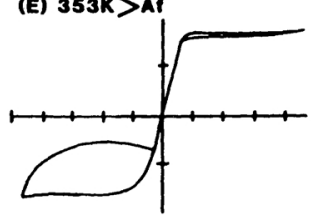

(C) $313 K, 1$ st cycle

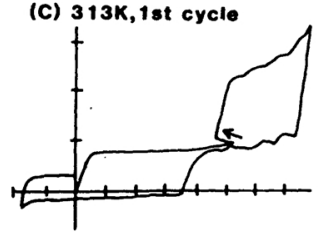

(c') $313 K, 2$ nd eycle

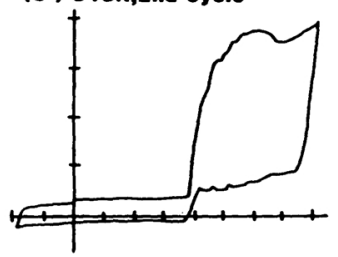

(F) $398 \mathrm{~K}$

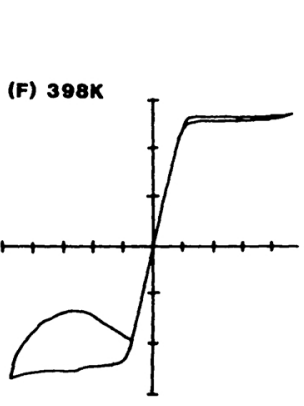

(B') $308 K$

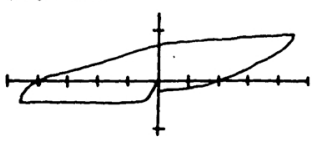

(I) Sp. 8, 348K >Af

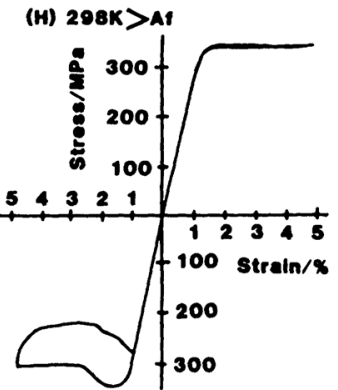

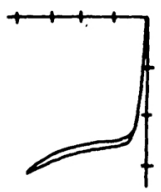

(J) Sp.9, 354.5K>Ai

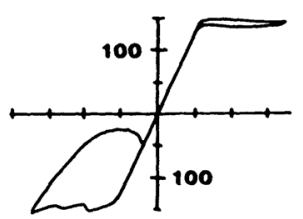

Fig. 4 (A) to (F): S-S curves for Sp. 1 as a function of temperature. (G) to (J): Other characteristic S-S curves. $(\mathrm{G})$ and $(\mathrm{H})$ are for Sp. 4, (I) is for Sp. 8, and (J) is for Sp. 9. See text for details.

twinning or detwinning takes place in the $\gamma_{1}^{\prime}$ martensite on the tension side. When deformation is started from the tension side and strain is given beyond $5 \%$ in the vicinity of $M_{s},(\mathrm{C})$, $\beta_{1} \rightarrow \beta_{1}^{\prime} \rightarrow \gamma_{1}^{\prime} \rightarrow \beta_{1}^{\prime \prime}$ transformations occur successively ${ }^{(15)}$. A characteristic feature of the S-S curve in $(C)$ is that strain decreases when the $\beta_{1}^{\prime} \rightarrow \gamma_{1}^{\prime}$ transformation occurs, as indicated by an arrow. If any extensometer were not used, the S-S curve would show only a sharp increase of stress ${ }^{(16)}$. Upon release of the stress, $\beta_{1}^{\prime \prime} \rightarrow \gamma_{1}^{\prime}$ transformation takes place, and a single variant of $\gamma_{1}^{\prime}$ martensite is finally obtained at zero stress. Then, twinning in the single variant of $\gamma_{1}^{\prime}$ martensite occurs on the compression side. $\left(C^{\prime}\right)$ shows a S-S curve obtained in the subsequent deformation cycle. Detailed description on the deformation behavior of the $\gamma_{1}^{\prime}$ martensite will be done elsewhere ${ }^{(17)}$.

\section{Effect of Al content and specimen orientation on $\mathrm{S}-\mathrm{S}$ behavior}

It has already been described ${ }^{(14)}$ that stress decreases when $\beta_{1} \rightarrow \gamma_{1}^{\prime}$ transformation is stress-induced. The amount of the stress decrease is influenced by the $\mathrm{Al}$ content. That is, the stress decrease is obvious in alloys with high $\mathrm{Al}$ content, as seen in Fig. 2 (Sp. 5; 15.1\% $\mathrm{Al})$ and Fig. $4(\mathrm{G})$ and $(\mathrm{H})(\mathrm{Sp} .4 ; 14.8 \% \mathrm{Al})$, but it is not nearly or at all in alloys with low $\mathrm{Al}$ content, as seen in Fig. 3 and Fig. 4(A) to (F) (Sp. 1; 13.8\%Al) and Fig. 4(J) (Sp. 9; $13.9 \% \mathrm{Al}$ ) (this S-S curve was obtained without extensometer), although the occurrence of $\beta_{1} \rightarrow \gamma_{1}^{\prime}$ transformation is evident from the existence of large hysteresis in those S-S curves. This indicates that $V_{i}$ of $\gamma_{1}^{\prime}$ martensite interfaces in high $\mathrm{Al}$ content alloys is larger than that in low $\mathrm{Al}$ content alloys, because the stress 
decrease takes place when $V_{i}$ is larger than $\dot{\varepsilon}^{(14)}$. Furthermore, it suggests that coherency at $\gamma_{1}^{\prime}$ martensite interfaces becomes better with increasing Al content, because good coherency may lead to a large $V_{i}$. Thus, $V_{i}$ is considered to depend upon the $\mathrm{Al}$ content as well as the crystal structure of $\operatorname{SIM}^{(14)}$.

The S-S bahavior on the compression side is also influenced by the specimen orientation, because the crystal structure of SIM changes depending on the orientation. In specimens with orientations relatively close to $\langle 001\rangle_{\beta_{1}}, \gamma_{1}^{\prime}$ martensite is usually stress-induced, but in specimens with orientations close to $\langle 011\rangle_{\beta_{1}}$ (for example, Sp. 8; Fig. 4(I) ${ }^{\dagger}$ ), $\beta_{1}^{\prime}$ martensite is stress-induced, as known from the appearance of pseudoelastic loops with small hysteresis, even though the specimens are deformed up to $4 \%$ strain. This result is in contrast to that previously reported by Martynov et $a l .{ }^{(18)}$, who found in their tensile tests that $\beta_{1} \rightarrow \beta_{1}^{\prime}$ transformation occurs in specimens with $\langle 001\rangle_{\beta_{1}}$ orientation and $\beta_{1} \rightarrow \gamma_{1}^{\prime}$ transformation in specimens with $\langle 001\rangle_{\beta_{1}}$ orientation. The difference between the present and previous experiments may possibly be attributed to the difference in the sense of stress.

\section{Macroscopic and microscopic observations of the SIM transformations}

Figure 5 is a series of photographs showing macroscopic morphological change during a tension-compression test. (a) shows a $\beta_{1}$ matrix state without external stress. Applying tensile stress, thin martensite plates of one variant are stress-induced, (b). Upon further loading, the specimen becomes a single crystal of the martensite, and this has been identified to be $\beta_{1}^{\prime}$ of a vriant with maximum Schmid's factor (S factor) $(+0.495)^{\dagger \dagger}$, from a back reflection Laue pattern (Fig. 6(a)) taken in the single crystal state under stress and from habit plane indices $\left((1 \overline{5} \overline{5})_{\beta_{1}}\right)$ determined by two surface

$\dagger$ Sp. 8 was unfortunately broken at a part near the grip, after it had been set to the machine. However, it was possible to perform the compressive test alone.

it Positive and negative $\mathrm{S}$ factors mean that a martensite variant is stress-induced on the tension and compression sides, respectively.

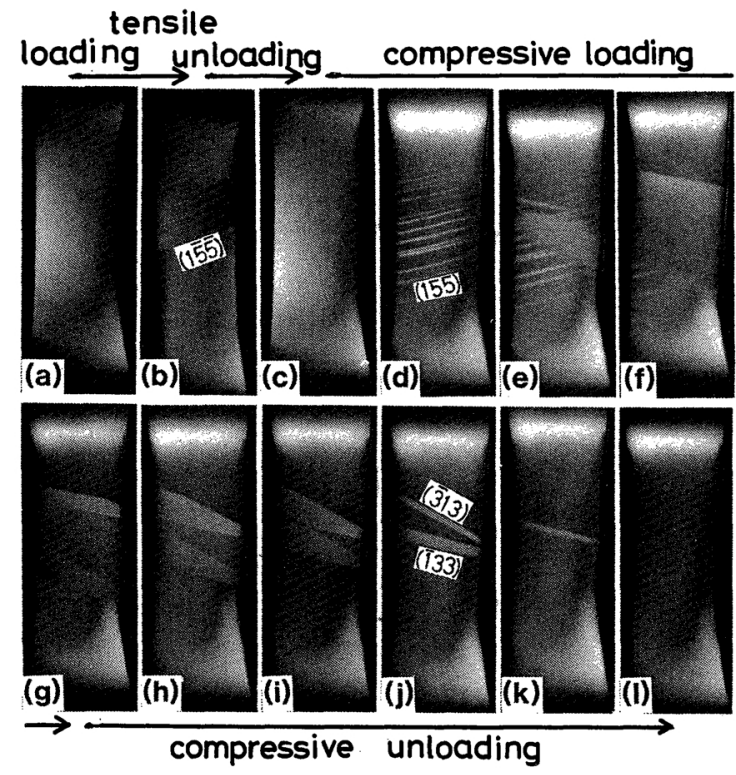

Fig. 5 Macroscopic morphological change during deformation at temperatures above $A_{\mathrm{f}}(\mathrm{Sp} .7$, side $\mathrm{A}$ ).

trace analysis. Upon unloading, the $\beta_{1}^{\prime}$ martensite transforms back to the $\beta_{1}$ matrix, (c). Applying compressive stress successively, a different variant of $\beta_{1}^{\prime}$ martensite is first stressinduced, which has a negative maximum $\mathrm{S}$ factor $(-0.460)$ and a habit plane of $(155)_{\beta_{1}}$. That is, the first formed SIM on both the tension and compression sides is $\beta_{1}^{\prime}$ with a maximum resolved shear stress. Subsequently, another variant of $\beta_{1}^{\prime}$, which has a secondly largest $S$ factor $(-0.456)$, is stress-induced, although its formation is too obscure to be visible in the photograph. The formation of two variants of $\beta_{1}^{\prime}$ martensites is due probably to an ill uniaxiality and the small difference (0.004) in S factor between the two variants on the compression side (corresponding difference on the tension side is as large as 0.012 ). Upon continued loading, a wide band of martensite is stress-induced as seen in (e). The martensite was identified to be $\gamma_{1}^{\prime}$, from a back reflection Laue pattern (Fig. 6(b)) taken from the singly oriented region in Fig. 5(e), being consistent with the $\mathrm{S}$ $\mathrm{S}$ curves in Fig. 3. Upon further loading, the $\gamma_{1}^{\prime}$ martensite grows at the expense of $\beta_{1}$ matrix and also $\beta_{1}^{\prime}$ martensite, (f) and (g). Upon release of the stress, (h) and (i), the still ex- 


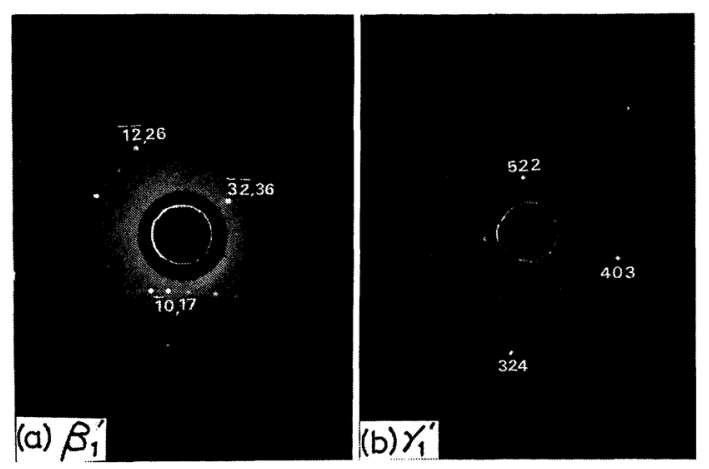

Fig. 6 (a) Laue pattern taken from a stress-induced $\beta_{1}^{\prime}$ martensite on tension. (b) Laue pattern taken from a single orientation region of $\gamma_{1}^{\prime}$ martensite shown in Fig. 7 (Sp. 7)

isting $\beta_{1}^{\prime}$ martensite first transforms back to $\beta_{1}$ matrix because of its small hysteresis of stress. The remaining $\gamma_{1}^{\prime}$ martensite takes such a form that two variants (I and II) of the martensite cross each other, as clearly seen in Fig. 7 which is a microstructure of crossed region covering the two surfaces of Sp. 7. The internal twinning plane of I variant is parallel to the habit plane of II variant, and vice versa, resulting in a single orientation in the crossed region. This morphology is identical to an X-interface found in In-Tl alloys ${ }^{(19)}$, and habit planes of I and II variants were determined to be $(\overline{1} 33)_{\beta_{1}}$ and $(\overline{3} 13)_{\beta_{1}}$, respectively. The aspect of this morphology suggests that internal twins correspond to a habit type intervariant interface ${ }^{(20)}$, and therefore, such twins may be called "habit type twins".

By the way, Funatsu et al. ${ }^{(21)}$ recently found that the second kind twin ${ }^{(22)}$ on $\{\overline{1}, 1.5036, \overline{0.5036}\}_{\gamma_{1}^{\prime}}$ was operative as deformation twins in a $\gamma_{1}^{\prime}$ single crystal martensite. Twinning planes of the present I and II variants are close to $(\overline{1}$, $\overline{1.5036}, \overline{0.5036})_{\gamma_{1}^{\prime}}$ and $(\overline{1}, \overline{1.5036}, 0.5036)_{\gamma_{1}^{\prime}}$, respectively, within $4^{\circ}-5^{\circ}$. Thus, the second kind twin on $\{\overline{1}, \overline{1.5036}, 0.5036\}_{\gamma_{1}^{\prime}}$ can be considered to constitute transformation twins in the present $\gamma_{1}^{\prime} \rightarrow \beta_{1}$ transformation, and the present habit type twins are of the second kind twins. Otsuka et al. ${ }^{(23)}$ has ever found transformation twins, whose plane deviated from $(121)_{\gamma_{1}^{\prime}}$ plane by $12.5^{\circ}$, during the reverse transformation from a single variant $\gamma_{1}^{\prime}$ martensite to $\beta_{1}$ matrix. Since the $(121)_{\gamma_{1}^{\prime}}$ plane makes an angle of $12.37^{\circ}$ from the $(1,1.5036,0.5036)_{\gamma_{1}^{\prime}}$ plane, the plane of transformation twins might be probably of the second kind twin.

Upon further unloading, both the two $\gamma_{1}^{\prime}$ variants schrink as seen in (j). II variant first disappears, (k), and I variant with a negative maximum $\mathrm{S}$ factor $(-0.467)$ finally disappears. Thus, the specimen perfectly reverts to the $\beta_{1}$ matrix, $(l)$.

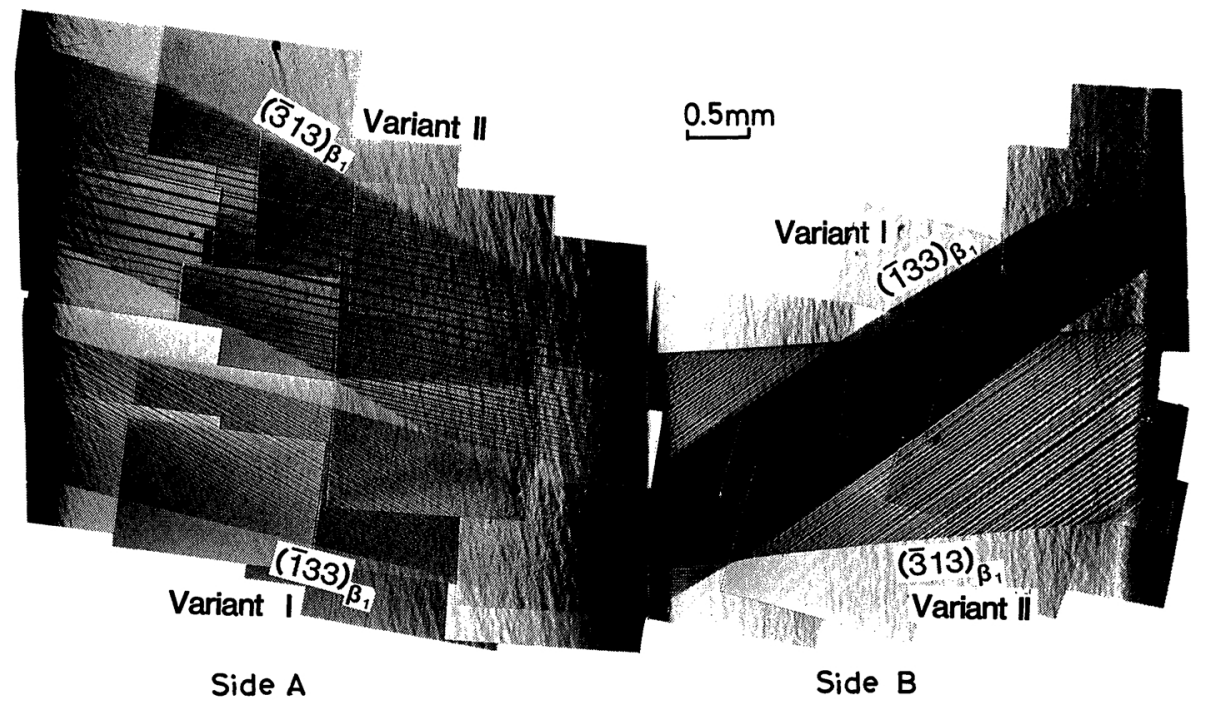

Fig. 7 Microstructure of a crossed region of two variants I and II upon compressive loading (Sp. 7, left: side A, right: side B). 


\section{Temperature dependence of critical stresses for inducing $\beta_{1}^{\prime}$ martensite}

There are two possible criteria as to the critical stresses $(\sigma)$ for SIM formation; C-C equation and Schmid's law. The former determines $d \sigma / d T$ from $\Delta \varepsilon$ and $\Delta H$ (latent heat) and the latter $\sigma$ from $S$ factor. However, the two criteria are incompatible with each other, because $\Delta \varepsilon^{\text {cal. }}$ is not exactly proportional to $S$ factor for SIM formation ${ }^{(14)}$. Therefore, close discussion is needed on such an incompatibility and precedence between the two criteria. However, it is hard in practice to discuss whether or not Schmid's law holds for SIM formation in tensile tests using various orientations of specimens. This is because the non-proportional term of $\Delta \varepsilon^{\text {cal. }}$ to $S$ factor is very small $^{(14)}$ and moreover $\sigma$ sensitively changes from specimen to specimen, depending on the difference between the test temperature and $M_{\mathrm{s}}$ point. However, a comparison between $\sigma_{t}$ and $\sigma_{c}$ in tension-compression tests enables one to do some discussion, since the same specimen is used in the tests. Then, $\sigma_{t}$ (or $d \sigma_{t} / d T$ ) and $\sigma_{c}$ $\left(d \sigma_{c} / d T\right)$ will be compared below.

Figure 8 shows the $d \sigma_{t} / d T$ and $d \sigma_{c} / d T$ for Sp. 1. Two characteristics are seen in the figure. One is that the $d \sigma_{c} / d T$ is larger than the $d \sigma_{t} / d T$, and the other is that the temperature given by extrapolation of $d \sigma_{c} / d T$ to zero stress is higher than that of $d \sigma_{t} / d T . d \tau_{t} / d T$ and $d \tau_{c} / d T^{\dagger}$ are also shown in Fig. 8 in relation to

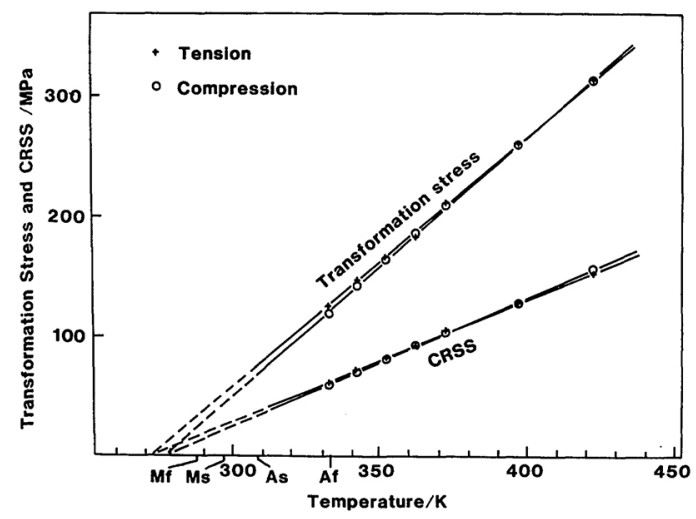

Fig. 8 Temperature dependence of critical transformation stresses and critical resolved shear stresses (CRSS) for inducing $\beta_{1}^{\prime}$ martensite (Sp. 1). the former point. If Schmid's law preceded for the SIM formation, $\tau_{t}$ and $\tau_{c}$ would be the same at each of test temperatures, and therefore, the $d \tau_{t} / d T$ and $d \tau_{c} / d T$ would be equal to each other. However, the $d \tau_{c} / d T$ is slightly larger than the $d \tau_{t} / d T$, and $\tau_{c}$ is smaller than $\tau_{t}$ at temperatures close to $M_{s}$ but is larger at temperatures above $\sim 360 \mathrm{~K}$. Similar results have been obtained for other five specimens, as shown in the left part of Table 2, the $d \tau_{c} / d T$ being always $3.5 \sim 6.9 \%$ larger than the $d \tau_{t} / d T$ regardless of $\mathrm{Al}$ content and specimen orientation. Therefore, the difference between $d \tau_{c} / d T$ and $d \tau_{t} / d T$ is due to a systematic deviation but not an experimental error. Thus, it can be concluded that $\tau$ changes depending upon the sense of stress and that Schmid's law itself does not hold in the present case.

Hereupon, a component of stress normal to the habit plane should be taken into consideration, because a volume change $(\Delta V)$ is associated with martensitic transformations. When $\Delta V>0$ (i.e. expansion), tensile stress is intuitively expected to have more favorable effect than compressive stress on SIM formation, leading to smaller $d \sigma_{t} / d T$ than $d \sigma_{c} / d T$, and when $\Delta V<0$ the reverse is the case. In fact, Patel and Cohen ${ }^{(8)}$ found in $\mathrm{Fe}-20 \% \mathrm{Ni}-$ $0.5 \% \mathrm{C}$ alloys $(\Delta V>0)$ that change in $M_{s}$ temperature under a tensile stress is larger than that under a compressive stress, that is $d \sigma_{t} / d T$ is smaller than $d \sigma_{c} / d T$. This result was theoretically explained in terms of some interaction among both the shear and normal components and transformation strain. According to the theory, $d \sigma_{c} / d T$ would be smaller than $d \sigma_{t} / d T$ in the present $\mathrm{Cu}-\mathrm{Al}-\mathrm{Ni}$ alloys since $\Delta V<0^{(24)}$. However, the experimental result is contrary to the expectation, and so it can not be explained by the Patel-Cohen theory.

Another possible explanation may be a stress concentration effect due to an ill uniaxiality under compressive stress. If a deviation of $0.83 \mathrm{~mm}$ exists in the direction perpendicular to stress axis, which is very likely, the

\footnotetext{
$\tau_{i}$ and $\tau_{c}$ were calculated assuming that $\beta_{1}^{\prime}$ martensite with a maximum $\mathrm{S}$ factor is first stress-induced, as actually verified in the previous section.
} 
stress concentration coefficient $\alpha$ is equal to 2 . This means that $\sigma_{c}$ and so $d \sigma_{c} / d T$ reduce to half since $\alpha$ is independent of temperature, and then the $d \sigma_{c} / d T$ may be expected to be smaller than $d \sigma_{t} / d T$. This is also contrary to the observation.

Therefore, the last probable explanation should be the one in terms of the $\mathrm{C}-\mathrm{C}$ equation, $d \sigma / d T=-\Delta H / T \Delta \varepsilon$. According to the equation, $d \sigma \Delta \varepsilon / d T(=-\Delta H / T)$ must be constant, because $\Delta H$ can be considered to be constant irrespective of the sense of stress. Therefore, $d \sigma_{c} \Delta \varepsilon_{\text {comp. }} / d T$ and $d \sigma_{t} \Delta \varepsilon_{\text {ten. }} / d T$ will be compared with each other on each of specimens tested. Results of the comparison are summarized in the right part of Table 2 . Comparison between values of $d \sigma \Delta \varepsilon^{\text {exp. }} / d T$ under tensile and compressive stresses is inappropriate, because $\Delta \varepsilon_{\text {comp. }}^{\text {exp. does not represent }}$ true $\Delta \varepsilon$ of $\beta_{1} \rightarrow \beta_{1}^{\prime}$ transformation as already mentioned, and naturally $d_{c} \Delta \varepsilon_{\text {comp. }}^{\text {exp. }} / d T$ markedly differs from $d \sigma_{t} \Delta \varepsilon_{\text {ten. }}^{\text {exp }} / d T$, as known from the table. On the other hand, comparison between values of $d \sigma \Delta \varepsilon^{\text {cal. }} / d T$, where the $\Delta \varepsilon^{\text {cal. }}$ is the one associated with $\beta_{1}^{\prime}$ martensite variant with a maximum $\mathrm{S}$ factor, has revealed that $d \sigma_{c} \Delta \varepsilon_{\text {comp. }}^{\text {cal. }} / d T$ coincides with $d \sigma_{t} \Delta \varepsilon_{\text {ten. }}^{\text {cal. }} / d T$ within a scatter of $+1.3-4.6 \%$ (positive sign means that the latter is larger than the former). The scatter can be regarded as an experimental error, since it is nearly symmetric over positive to negative and is smaller than that between $d \sigma_{c} / d T$ and $d \sigma_{t} / d T$. It may, thus, be concluded that $d \sigma \Delta \varepsilon^{\text {cal. }} / d T$ is constant irrespective of the sense of stress, and that $\mathrm{C}-\mathrm{C}$ equation precedes in the present tests. Therefore, $d \sigma_{c} / d T$ becomes larger than $d \sigma_{t} / d T$, as actually seen in Fig. 8 , since $\Delta \varepsilon_{\text {ten. }}^{\text {cal. is generally larger }}$ than $\Delta \varepsilon_{\text {comp. }}^{\text {cal. }}$ as already mentioned.

Schmid's law may be simply imagined to be preceded in the present $\mathrm{Cu}-\mathrm{Al}-\mathrm{Ni}$ alloys, since $\Delta V$ is very samll and, therefore, the shear component of stress obviously operates more effectively than the normal component upon SIM formation. However, the above conclusion indicates that transformation stress can not be directly determined from Schmid's law, and that it can be from C-C equation through $\Delta \varepsilon$ associated with the first formed $\beta_{1}^{\prime}$ martensite variant with a maximum $\mathrm{S}$ factor. Only in such a form, Schmid's law is concerned with SIM formation, because it is originally a criterion for slip deformation but not for deformation due to SIM formation. It can also be known from the above conclusion that S-S curves at an arbitrary temperature never show a perfect symmetry on the tension and compression sides even if only $\beta_{1} \rightarrow \beta_{1}^{\prime}$ transformation occurs on the compression side, because $\sigma_{t}$ is lower or higher than $\sigma_{c}$ at the temperature.

The last point to be discussed is a difference between temperatures given by extrapolation of $d \sigma / d T$ to zero stress. The difference is probably ascribed to a difference in constraint conditions of specimen grips between tension and compression, and this is schematically shown in Fig. 9. When a SIM forms, displacements should take place in the perpendicular direction besides the parallel one to stress axis. The perpendicular displacement on compression has an opposite effect to that on a tension. That is, the former easily operates as a mechanism to avoid a stress increase, but the latter does not. Therefore, SIM may form at a lower stress level on compression, but at a higher level on tension, both being independent of test temperature. This may lead to the result that the temperature given by extrapolation of $d \sigma_{c} / d T$ to zero stress is higher than that of $d \sigma_{t} / d T$.

\section{Acknowledgements}

The authors are grateful to Prof. K. Otsuka and Dr. S. Miyazaki at University of Tsukuba for useful discussion and to Mr. T. Toshiki for specimen preparation and technical assistance.

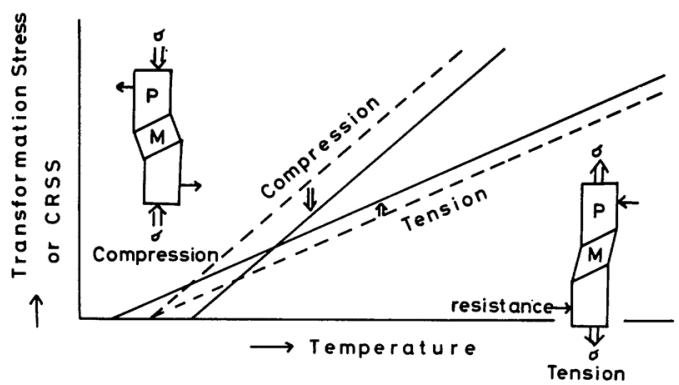

Fig. 9 Schematic illustration of different effects of tensile and compressive stresses on transformation stress (dotted lines indicate hypothetical $d \sigma / d T$ in the absence of constraint effect). 
The present work was partly supported by the Research Project of the ISIR, Osaka University, on "Development of New Materials for Energy Conversion".

\section{REFERENCES}

(1) K. Otsuka and C. M. Wayman: Reviews on the Deformation Behavior of Materials (Ed. by P. Feltham), Israel, (1977) (Freund Publ. House), 2 (2), p. 98.

(2) K. Otsuka and K. Shimizu: Metals Forum, 4 (1981), 142.

(3) A. Sato and M. Kato: Tetsu to Hagané, 69 (1983), 1531 (in Japanese).

(4) F. Falk: Acta Met., 28 (1980), 1773.

(5) M. Wuttig and Te. Suzuki: Met. Trans., 12A (1981), 1362.

(6) M. Achenbach and I. Muller: Proc. ICOMAT-82, (Leuven), Suppl. to J. de Physique, 43 (1982), C4163.

(7) M. W. Burkart and T. A. Read: Trans. Met. Soc. AIME, 197 (1953), 1516.

(8) J. R. Patel and M. Cohen: Acta Met., 1 (1953), 531.

(9) H. Pops: Met. Trans., 1 (1970), 251.

(10) Y. Murakami: J. Phys. Soc. Jpn., 33 (1972), 1350.

(11) N. Nakanishi, T. Mori, S. Miura, Y. Murakami and S. Kachi: Phil. Mag., 28 (1983), 277.

(12) H. Sakamoto, M. Tanigawa and K. Otsuka and K.
Shimizu: Proc. ICOMAT-79, (Cambridge, U.S.A.), p. 633.

(13) H. Sakamoto, M. Tanigawa and K. Shimizu: Suppl. to Sci. Rep. RITU, A29 (1981), 91.

(14) K. Otsuka, C. M. Wayman, K. Nakai, H. Sakamoto and K. Shimizu: Acta Met., 24 (1976), 207.

(15) K. Otsuka, H. Sakamoto and K. Shimizu: Acta Met., 27 (1979), 585.

(16) K. Otsuka, H. Sakamoto and K. Shimizu: Scripta Met., 10 (1976), 983.

(17) H. Sakamoto and K. Shimizu: in preparation.

(18) V. V. Martynov, L. G. Khandros and A. V. Tkachenko: Scripta Met., 17 (1983), 1173.

(19) Z. S. Basinski and J. W. Christian: Acta Met., 2 (1954), 148.

(20) H. Tas, L. Delaey and A. Deruyttere: Z. Metallk., 64 (1973), 855.

(21) H. Funatsu, S. Ichinose and K. Otsuka: Collected Abstracts of the 1983 Autumn Meeting of Japan Inst. Metals, p.364 (in Japanese).

(22) B. A. Bilby and A. G. Crocker: Proc. Roy. Soc. (London), A288 (1965), 240.

(23) K. Otsuka, K. Shimizu and M. Takahashi: Proc. Int. Conf. on Crystal Growth, (1974), Collected Abstracts, p. 191.

(24) K. Otsuka and K. Shimizu: Trans. JIM, 15 (1974), 103. 